\title{
A Phase II Study of Erlotinib in Patients with Previously Treated Non-Small Cell Lung Cancer
}

\author{
Tetsuya Kubota ${ }^{*}$, Yoshio Okano², Mizu Sakai1, Takashi Yamane1, Naoki Shiota1, \\ Hiroshi Ohnishi' ${ }^{1}$, Hisanori Machida², Nobuo Hatakeyama ${ }^{2}$, Eiji Takeuchi ${ }^{3}$, \\ Tomoyuki Urata ${ }^{4}$, Fumitaka Ogushi' ${ }^{2}$, Akihito Yokoyama ${ }^{1}$ \\ ${ }^{1}$ Department of Hematology and Respiratory Medicine, School of Medicine, Kochi University, Kochi, Japan \\ ${ }^{2}$ Division of Pulmonary Medicine, NHO Kochi Hospital, Kochi, Japan \\ ${ }^{3}$ Division of Pulmonary Medicine, Kochi Red Cross Hospital, Kochi, Japan \\ ${ }^{4}$ Division of Pulmonary Medicine, Kochi Medical Center, Kochi, Japan \\ Email: ${ }^{*}$ kubotat@kochi-u.ac.jp
}

Received 1 January 2014; revised 2 February 2014; accepted 10 February 2014

Copyright (C) 2014 by authors and Scientific Research Publishing Inc.

This work is licensed under the Creative Commons Attribution International License (CC BY). http://creativecommons.org/licenses/by/4.0/

c) (i) Open Access

\section{Abstract}

Background: Erlotinib has been reported to be effective for the treatment of non-small cell lung cancer (NSCLC). To evaluate the efficacy and safety of erlotinib under conditions similar to daily clinical practice, a phase II trial was conducted in Japanese patients with previously treated NSCLC. Methods: The eligibility criteria were stage IIIB/IV NSCLC, a performance status (PS) of 0 - 2, and previous treatment with 1 - 2 non-EGFR-TKI regimens. Patients received erlotinib $(150 \mathrm{mg} / \mathrm{day})$ orally until disease progression or intolerable toxicity occurred. The primary endpoint was the objective response rate (ORR). In addition, the disease control rate (DCR), progression-free survival (PFS), overall survival (OS), safety, and EGFR gene mutation status were evaluated. Results: Thirty-eight patients were enrolled, and 37 patients were evaluated. The median age was 69 years (range, 50 - 80 years). Patient characteristics were as follows: 26 were male and 11 were female; 12 had a PS of 0, 20 had a PS of 1, and 5 had a PS of 2; and 26 had adenocarcinoma, and 11 had non-adenocarcinoma histology. The ORR and DCR were $21.6 \%$ (95\% confidence interval [CI], $11.4 \%$ - $37.2 \%)$ and $54.1 \%(95 \% \mathrm{CI}, 35.9 \%-66.6 \%)$, respectively. Twenty-seven patients could be evaluated for EGFR gene status (12, mutated; 15, wild-type). The ORR for EGFR-mutated patients was $41.7 \%$, while that for patients with wild-type EGFR was $13.3 \%$. The median PFS was evaluated as 4.4 months (95\% CI, 2.2 - 10.7 months). The median OS was 14.9 months (95\% CI, 9.2 months - not reached). Common adverse events were tolerable skin toxicities, diarrhea, and stomatitis. In addition, interstitial lung disease occurred in $8.1 \%$ of patients. Conclusion: As efficacy and safety were similar to previous studies, erlotinib was found to be effective for Japanese patients with

\footnotetext{
"Corresponding author.
}

How to cite this paper: Kubota, T., Okano, Y., Sakai, M., Yamane, T., Shiota, N., Ohnishi, H., Machida, H., Hatakeyama, N., Takeuchi, E., Urata, T., Ogushi, F. and Yokoyama, A. (2014) A Phase II Study of Erlotinib in Patients with Previously Treated Non-Small Cell Lung Cancer. Advances in Lung Cancer, 3, 10-20. http://dx.doi.org/10.4236/alc.2014.31002 
previously treated NSCLC in clinical practice.

Keywords

Non-Small Cell Lung Cancer; Phase II Study; Erlotinib; Previously Treated

\section{Introduction}

Lung cancer is currently the leading cause of cancer-related deaths in Japan [1] and worldwide [2], as it has been for years. Among lung cancer subtypes, non-small cell lung cancer (NSCLC) is the most common form (approximately 85\%), with many patients presenting with advanced disease at initial diagnosis [3]. Advanced NSCLC is currently considered an incurable disease for which standard chemotherapy provides marginal improvement in overall survival. A combination of platinum chemotherapy with a third-generation agent has been established as a standard first-line regimen with a 1-year survival rate of approximately 33\% [4]. Recent advances in chemotherapy and targeted therapy now provide new treatment options for the disease. One example is the orally administered epidermal growth factor receptor (EGFR)-tyrosine kinase inhibitor (TKI) agent [5].

Erlotinib, an oral EGFR-TKI, demonstrated a significant survival benefit versus placebo in patients with previously treated advanced NSCLC in the pivotal trial BR.21 [6]. In that trial, erlotinib was associated with superior survival in unselected patients (6.67 months for erlotinib versus 4.70 months for placebo). Accordingly, erlotinib was approved by the Food and Drug Administration in 2004 for the treatment of patients with advanced NSCLC who have failed at least 1 prior chemotherapy regimen [7]. Thereafter, EGFR-TKIs, including erlotinib, have become promising therapeutic options for patients with advanced NSCLC [8], especially in Asian populations [9]-[11]. The efficacy of EGFR-TKIs is strongly associated with EGFR-sensitive mutation status in patients with NSCLC [7]-[11]. However, recent studies demonstrated that erlotinib showed modest but apparent beneficial effects in NSCLC patients with wild-type EGFR as well [12] [13]. It is important to understand the benefit of erlotinib under conditions similar to daily clinical practice, such as in a patient population with unselected EGFR gene status, unselected histology, and unlimited age. To date, a few prospective studies of erlotinib monotherapy for Japanese pretreated NSCLC patients have been reported [14]-[16]. Therefore, we performed this prospective, multicenter, phase II, open-label study to investigate the efficacy and tolerability of erlotinib monotherapy in Japanese patients with pretreated NSCLC, regardless of EGFR gene mutation status.

\section{Patients and Methods}

\subsection{Patients Eligibility and Selection}

Patients were required to fulfill the following eligibility criteria: pathologically (either cytologically or histologically) proven stage IIIB/IV NSCLC, measurable lesion(s) defined by Response Evaluation Criteria in Solid Tumors (RECIST), history of refractory treatment with 1 or 2 chemotherapy regimens but no prior EGFR-TKI therapy, age more than 20 years, Eastern Cooperative Oncology Group (ECOG) performance status (PS) of 0 - 2, and an expected survival of at least 3 months. In addition, other eligibility criteria with respect to organ function were as follows: adequate bone marrow functions (leukocyte count, $4000-12,000 / \mu \mathrm{L}$; absolute neutrophil count, $\geq 1500 / \mu \mathrm{L}$; and platelet count $\geq 100,000 / \mu \mathrm{L}$ ), adequate respiratory function (arterial oxygen saturation, $>90 \%$ while breathing ambient air), adequate liver function (levels of asparate aminotransferase and alanine aminotransferase, $<2 \times$ upper limit of normal [ULN]; and total bilirubin, $<1.5 \mathrm{mg} / \mathrm{dL}$ ), and adequate renal function (serum creatinine, $<1.5 \times$ ULN). Baseline chest computed tomography (CT) had to have been performed within 4 weeks before study registration. The study could not be initiated earlier than 3 weeks after the last dose of chemotherapy. Likewise, thoracic radiotherapy was required to have been completed at least 12 weeks prior to the study. Exclusion criteria were as follows: pregnancy, concomitant malignancy, pleural effusion requiring treatment, symptomatic cerebral involvement, history of using anti-HER2 agents, and prior and/or existing interstitial lung disease (ILD) including active radiation pneumonitis. Use of either concomitant anticancer treatment or preventive treatment for adverse events was not allowed. This study was performed in accordance with the World Medical Association Declaration of Helsinki (1964, amended in 2000). All enrolled patients provided 
written informed consent. The protocol was approved by the Institutional Review Board of all participating institutions.

\subsection{Treatment Regimen}

Erlotinib was administered orally at a daily dose of $150 \mathrm{mg}$. Two-step reduction doses (first reduction, 100 $\mathrm{mg} /$ day; second reduction; $50 \mathrm{mg} /$ day) were permitted per patient, according to treatment-related toxicities. For example when grade 3 or intolerable grade 2 rash or stomatitis occurred, treatment was withheld until symptoms improved to grade 1 severity or less, and erlotinib was resumed with a 1-step dose reduction. When grade 3 diarrhea occurred, treatment was stopped until improvement to grade 1 severity or less, and therapy was then resumed with a 1-step reduction. The therapy was continued until either disease progression or unacceptable toxicity occurred. No dose escalations were permitted. When either ILD of any grade or any other grade 4 toxicities occurred, erlotinib treatment was permanently discontinued.

\subsection{Assessment of Antitumor Activity and Toxicity}

Chest radiography, complete blood counts, and blood chemistry studies were performed at least every 2 weeks. CT for the assessment of target or non-target lesions was designed to be performed every 4 weeks. The RECIST was used to evaluate responses. Complete and partial responses were determined by 2 assessments not less than 4 weeks apart. A response designation of stable disease (SD) required tumor stabilization for at least 6 weeks. All toxicities were graded according to the National Cancer Institute Common Terminology Criteria for Adverse Events v3.0.

\subsection{EGFR Analysis}

EGFR gene mutation status was evaluated when suitable tumor tissues at initial diagnosis or surgery were available. Either paraffin-embedded tissues or fresh frozen samples were used for commercial analysis using either the cycleave polymerase chain reaction (PCR) method [17] or the real-time PCR-based peptide nucleic acid-locked nucleic acid PCR clamp method [18].

\subsection{Statistics}

This clinical trial was designed to assess the objective response rate (ORR) for erlotinib monotherapy as the primary endpoint. Secondary endpoints were the disease control rate (DCR), progression-free survival (PFS), overall survival (OS), and toxicities. The sample size was calculated using Fisher's exact test. According to previous clinical trials of erlotinib for NSCLC in BR.21 [6] and in Japanese patients [14] [15], the response rate ranges from $8.9 \%$ to $28 \%$. On the basis of a 1 -sided calculation $(\alpha=0.05,1-\beta=0.9)$ with a null proportion of 0.28 and an alternative proportion of 0.089 , the minimum sample number was assumed to be 34 . Consequently, 38 patients were recruited to allow for patient dropouts. The 95\% confidence interval (CI) for ORR and DCR was determined using the Clopper-Pearson method. The time-to-event variables were calculated using the Kaplan-Meier method. Statistical significance was evaluated using the log-rank test. $P<0.05$ was considered significant. The best response and OS were estimated using logistic regression and Cox proportion hazards regression methods, respectively. This study was registered with the University Hospital Medical Information Network (UMIN) in Japan (number UMIN000002735).

\section{RESULTS}

\subsection{Patient Characteristics}

A total of 38 Japanese patients from 4 institutions were enrolled in this study between July 2009 and February 2011. Thirty-seven patients were evaluable for efficacy and safety. One patient was excluded because of protocol violation. The baseline clinical characteristics of the patients are summarized in Table 1 . The median patient age was 69 years (range, 50 - 80 years), and $70.3 \%$ of the patients were male. Twenty-six patients (70.3\%) had adenocarcinoma, and 14 patients (37.8\%) had no history of smoking. Twenty-six patients (70.3\%) had received only first-line chemotherapy. 
Table 1. Summary of patient characteristics.

\begin{tabular}{|c|c|}
\hline Number of patients & 37 \\
\hline \multicolumn{2}{|l|}{ Age (years) } \\
\hline Median (Range) & $69.0(50-80)$ \\
\hline \multicolumn{2}{|l|}{ Sex } \\
\hline Male & $26(70.3 \%)$ \\
\hline Female & $11(29.7 \%)$ \\
\hline \multicolumn{2}{|l|}{ Performance status } \\
\hline 0 & $12(32.4 \%)$ \\
\hline 1 & $20(54.1 \%)$ \\
\hline 2 & $5(13.5 \%)$ \\
\hline \multicolumn{2}{|l|}{ Histology } \\
\hline Adenocarcinoma & $26(70.3 \%)$ \\
\hline Squamous cell carcinoma & $6(16.2 \%)$ \\
\hline Unclassified & $5(13.5 \%)$ \\
\hline \multicolumn{2}{|l|}{ Stage } \\
\hline IIIB & $8(21.6 \%)$ \\
\hline IV & $29(78.4 \%)$ \\
\hline \multicolumn{2}{|l|}{ Smoking history } \\
\hline Never & $14(37.8 \%)$ \\
\hline Current or former & $22(59.5 \%)$ \\
\hline Uncertainty & $1(2.7 \%)$ \\
\hline \multicolumn{2}{|c|}{ Number of prior chemotherapy regimen(s) } \\
\hline 1 & $26(70.3 \%)$ \\
\hline 2 & $11(29.7 \%)$ \\
\hline \multicolumn{2}{|l|}{$E G F R$ gene status } \\
\hline Mutated (sensitive mutation) & $12(32.4 \%)$ \\
\hline Wild-type & 15 (40.5\%) \\
\hline Unknown & $10(27.0 \%)$ \\
\hline
\end{tabular}

\subsection{Clinical Outcome}

The tumor response rates are shown in Table 2. Although no patients achieved complete response, 8 patients (21.6\%) were assessed as having partial response (PR) and 12 patients (32.4\%) were assessed as having SD. In 6 patients, the objective response could not be confirmed: in 4 cases, erlotinib was discontinued early after the initiation of therapy because of patient refusal, and in 2 patients, therapy had to be stopped because of either ILD or severe rash. The ORR was $21.6 \%$ (95\% CI, 11.4\% - 37.2\%), and the DCR was 54.1\% (95\% CI, 35.9\% 66.6\%). The median PFS was 4.4 months (95\% CI, 2.2 - 10.7 months) (Figure 1(a)). The OS was determined based on information collected until the follow-up survey in February 2012. The median survival time from enrollment was 14.9 months (95\% CI, 9.2 - not reached), and the 1-year survival rate was 56.6\% (95\% CI, 38.4\% - 71.2\%) (Figure 1(b)). As shown in Figure 2, the median survival times varied among cohorts: 23.2 months (95\% CI, 2.3 - not reached) and 12.3 months (95\% CI, 5.3 - not reached) in female and male patients $(P=0.419)$, Not reached (95\% CI, 5.9 - not reached), and 11.4 months (95\% CI, 3.8 - 16.3) in non-smokers and smokers (current or former) $(P=0.0369)$, and 23.2 months $(95 \% \mathrm{CI}$, 9.2 - not reached) and 12.3 months (95\% CI, not reached) in patients with adenocarcinoma and squamous cell carcinoma histology $(P=0.018)$, respectively. In some cohorts, survival times could not be determined because they were not reached during the observation period. These results suggested that patients with characteristics of female gender, non-smoking history, and adenocarcinoma histology showed better response rates than did others. As for previous chemotherapy regimens, 
Table 2. Response assessment.

\begin{tabular}{ll}
\hline Partial response & $8(21.6 \%)$ \\
Stable disease & $12(32.4 \%)$ \\
Progressive disease & $11(29.7 \%)$ \\
Not evaluated & $6(16.2 \%)$ \\
Objective RR (95\% CI) & $21.6 \%(11.4-37.2)$ \\
Disease control rate (95\% CI) & $54.1 \%(35.9-66.6)$ \\
1-year survival & $56.6 \%(38.4-71.2)$ \\
Median PFS (95\% CI) & \\
$\quad$ Non-selected & 4.4 months $(2.2-10.7)$ \\
$\quad$ EGFR mutated & 12.6 months $(2.2-19.9)$ \\
$\quad$ EGFR wild-type & 2.1 months $(1.0-5.5)$ \\
Median OS (95\% CI) & 3.9 months $(1.0-11.0)$ \\
$\quad$ Non-selected & \\
EGFR mutated & 14.9 months $(9.2-\mathrm{NR})$ \\
EGFR wild-type & NR (5.3 - NR) \\
EGFR unknown & 9.2 months $(2.3-14.9)$ \\
\hline
\end{tabular}

$\mathrm{RR}$, response rate; CI, confidence interval; PFS, progression-free survival; OS, overall survival; NR, not reached.

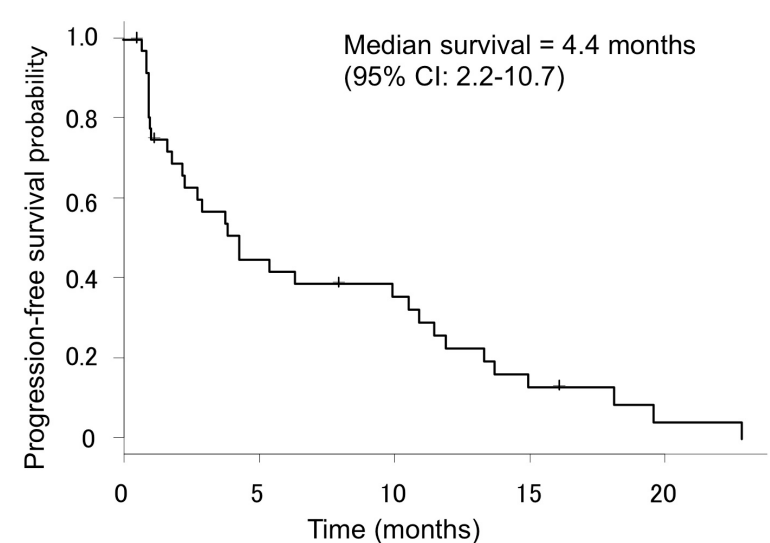

Number at risk

37 15
4

(a)

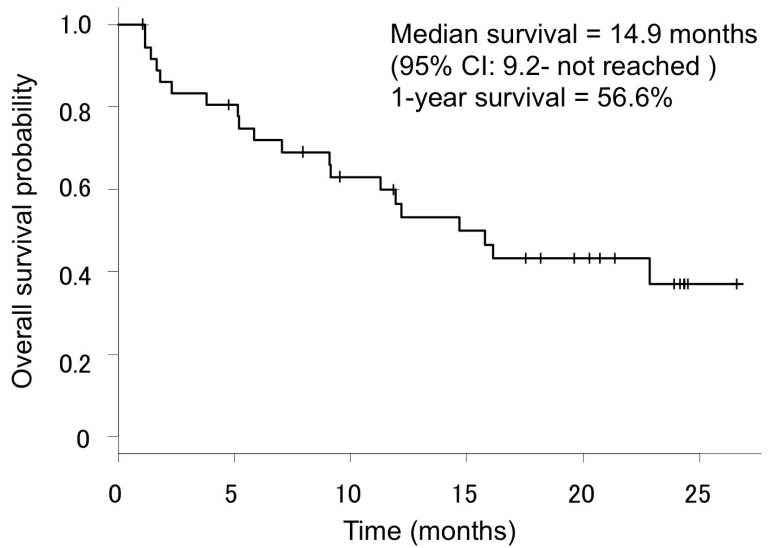

Number at risk

$37 \quad 28$

(b)

Figure 1. Progression-free survival (a) and overall survival (b) of all patients. The median PFS time, OS time, and 1-year survival rate were 4.4 months, 14.9 months, and 56.6\%, respectively. CI, confidence interval.

our data showed no significant differences in either response rate or survival between patients with 1 prior regimen $(n=26)$ and those with 2 prior regimens $(n=11)(P=0.13$, data not shown).

\subsection{Safety}

As shown in Table 3, adverse events were observed in all patients. The most common adverse events were skin disorders (70.3\%). Other adverse events, including stomatitis (35.1\%) and diarrhea (24.3\%), were often observed. Liver dysfunction was observed in $8.1 \%$ of patients; however, no patients showed elevation of transaminase levels of grade 3 severity or higher. Skin toxicities were well tolerated and reversible with either appropriate skin treatment or dose reduction. Six patients $(16.2 \%)$ had dose reductions because of rash $(\mathrm{n}=2)$ and diarrhea, fatigue, anorexia, or infectious enterocolitis. Unfortunately, 8 patients (21.6\%) discontinued erlotinib therapy because of adverse events, including anorexia $(n=3)$, ILD $(n=2)$, rash $(n=2)$, and diarrhea $(n=1)$. Interestingly, a stratified Kaplan-Meier analysis demonstrated that patients with rash of grade 2 severity or 

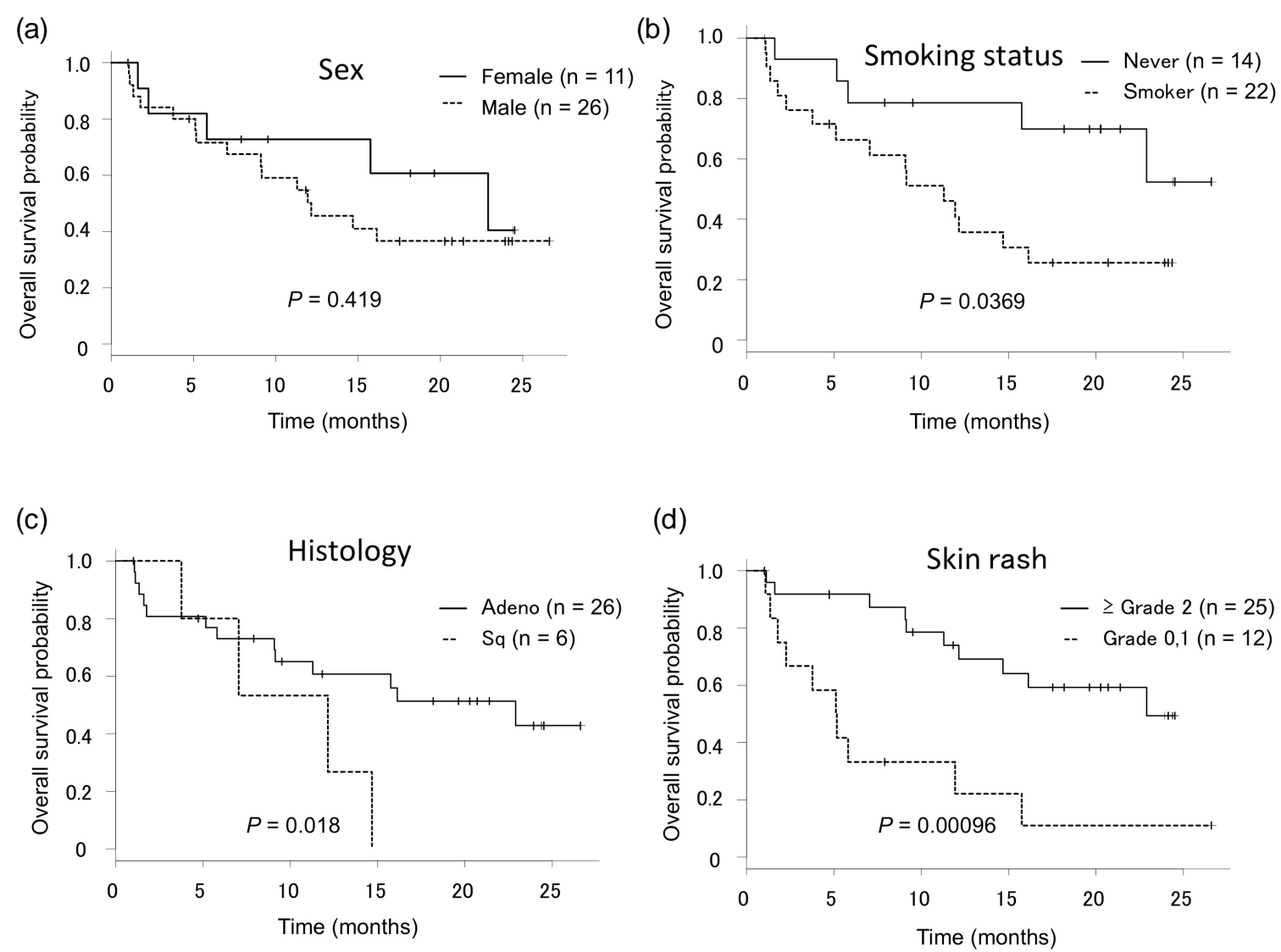

Figure 2. Overall survival curves according to clinical characteristics. (a) Sex (female versus male, $P=0.419$ ). (b) Smoking status. Smokers include current smokers and former smokers (never smoker versus smoker, $P=0.0369$ ). (c), Histology (adeno versus sq, $P=0.018$ ). (d), Skin rash (grade 2 or higher versus grade 0 and $1, P=0.00096$ ). $P<0.05$ was considered significant. Statistical analyses were performed using the log-rank test. adeno, adenocarcinoma; sq, squamous cell carcinoma.

higher $(n=25)$ showed significantly improved survivals compared with those with rash of grade 1 severity or those without rash $(\mathrm{n}=12)(P=0.00096)$ (Figure 2(d)). The median OS was 696 days (23.2 months) for those with severe rash and 157 days (5.2 months) for those with non-severe or no rash.

Regrettably, 3 patients (8.1\%) experienced ILD events, and 1 of these patients died of acute respiratory failure. The characteristics of these patients are summarized in Table 4. All 3 patients were male, and their PS was 0 - 1. Two of these patients were former smokers, while 1 had no history of smoking. The patient who died of ILD was a 69-year-old man with adenocarcinoma; he had a 99-pack-year history (3 packs/day $\times 33$ years). He discontinued erlotinib treatment on day 23 because of tumor progression. Despite treatment cessation, he developed ILD on day 36; a chest high-resolution CT scan revealed a pattern of acute interstitial pneumonia, compatible with drug-induced ILD. Immediate steroid pulse therapy was started, together with oxygen therapy plus ampicillin/sulbactam. An autopsy could not be performed. We considered this adverse event to be erlotinib related.

\subsection{EGFR Analysis}

In this study, a total of 27 samples (73\%) were available for EGFR gene mutation analyses. All analyses were performed commercially as part of routine clinical practice. Fifteen patients (55.6\%) had wild-type EGFR status, and 12 patients (44.4\%) had mutated EGFR status. Of the 12 mutations (8 in male and 4 in female patients), 6 were exon 19 deletions, 5 were L858R point mutations in exon 21, and 1 was a double mutation of an exon 19 deletion plus a L858R point mutation. With regard to the association between responses and mutation types, patients with EGFR mutations showed various responses. Of the 6 patients with exon 19 deletions, the response was a $\mathrm{PR}$ in 1 patient, SD in 3 patients, progressive disease (PD) in 1 patient, and not evaluated (NE) in 1 patient. 
Of the 5 patients with L858R, PR was noted in 3 patients and SD was noted in 2. The 1 patient with double mutations achieved PR. Taken together, the response in these patients with EGFR mutations was PR in 5 cases, SD in 5 cases, and NE in 1 case. Of the 12 cases, 11 (91.7\%) were of adenocarcinoma and 1 was of unclassified NSCLC. Eight patients (66.7\%) had no history of smoking, 4 patients (33.3\%) were former smokers, and no patients were current smokers.

The PFS of patients with EGFR mutations was analyzed and compared with that of wild-type EGFR patients (Table 2). As expected, patients with EGFR mutations demonstrated longer survival times than did those with wild-type EGFR. The median PFS in EGFR mutation-positive patients was 12.6 months (95\% CI, 2.2 - 19.9); meanwhile, PFS in patients with wild-type EGFR was 2.1 months (95\% CI, 1.0 - 5.5), and that in patients with unknown-type EGFR was 3.9 months (95\% CI, 1.0 - 11.1). A statistically significant difference in PFS was noted between patients with EGFR mutations and those with wild-type EGFR $(P=0.00441)$. However, no significant difference was detected between patients with unknown-type and wild-type EGFR.

We also evaluated OS in patients with EGFR mutations. As shown in Figure 3, Kaplan-Meier analysis revealed a survival advantage for patients with EGFR mutations, compared with patients lacking EGFR mutations. The median OS in patients with EGFR mutations was not yet reached: however, median OS in patients with wild-type and unknown-type EGFR was 9.2 months (95\% CI, 2.3 - 14.9) and 12.3 months (95\% CI, 1.1 - not reached), respectively (Table 2). Statistically significant differences in OS were detected between patients with and without mutations $(P=0.0115)$. However, no significant difference was noted between patients with unknown status and those with wild-type EGFR.

\begin{tabular}{|c|c|c|c|c|}
\hline \multirow{2}{*}{$\begin{array}{c}\text { Toxicity } \\
\text { grade (CTCAE) }\end{array}$} & \multicolumn{4}{|c|}{ Number of patients } \\
\hline & 1 & 2 & 3 & $\geq 4$ \\
\hline \multicolumn{5}{|l|}{ Skin disorder } \\
\hline Rash & $12(32.4 \%)$ & $14(37.8 \%)$ & 0 & 0 \\
\hline Acne-like rash & $2(5.4 \%)$ & $5(13.5 \%)$ & 0 & 0 \\
\hline Dryness & $6(16.2 \%)$ & $4(10.8 \%)$ & 0 & - \\
\hline Pruritus & $4(10.8 \%)$ & $4(10.8 \%)$ & 0 & - \\
\hline Paronychia & $2(5.4 \%)$ & $2(5.4 \%)$ & 0 & 0 \\
\hline Pyoderma & 0 & $2(5.4 \%)$ & 0 & 0 \\
\hline Stomatitis & 9 (24.3\%) & $3(8.1 \%)$ & $1(2.7 \%)$ & 0 \\
\hline Diarrhea & 7 (18.9\%) & $1(2.7 \%)$ & $1(2.7 \%)$ & 0 \\
\hline Anorexia & $1(2.7 \%)$ & $1(2.7 \%)$ & $1(2.7 \%)$ & $1(2.7 \%)$ \\
\hline Fever & $4(10.8 \%)$ & 0 & 0 & 0 \\
\hline Pneumonitis & $2(5.4 \%)$ & 0 & 0 & $1(2.7 \%)$ \\
\hline Nausea & $3(8.1 \%)$ & 0 & 0 & 0 \\
\hline Pharyngitis & $3(8.1 \%)$ & 0 & 0 & 0 \\
\hline Liver injury & $3(8.1 \%)$ & 0 & 0 & 0 \\
\hline Fatigue & 0 & $1(2.7 \%)$ & $1(2.7 \%)$ & 0 \\
\hline Conjunctivitis & $2(5.4 \%)$ & 0 & - & - \\
\hline
\end{tabular}

CTCAE, common terminology criteria for adverse events.

Table 4. Characteristics of 3 cases showing treatment-related interstitial lung disease-like events.

\begin{tabular}{cccccc}
\hline Age/Sex & Smoking & PS & Histology & Onset (day) & Outcome \\
\hline $63 \mathrm{M}$ & Former & 1 & Ad & 14 & Recovered \\
$69 \mathrm{M}$ & Former & 1 & Ad & 21 & Died (day 42) \\
$70 \mathrm{M}$ & Never & 0 & Ad & $262^{*}$ & Recovered \\
\hline
\end{tabular}

*Causal relation to erlotinib is undeniable. PS, performance status; Ad, adenocarcinoma. 


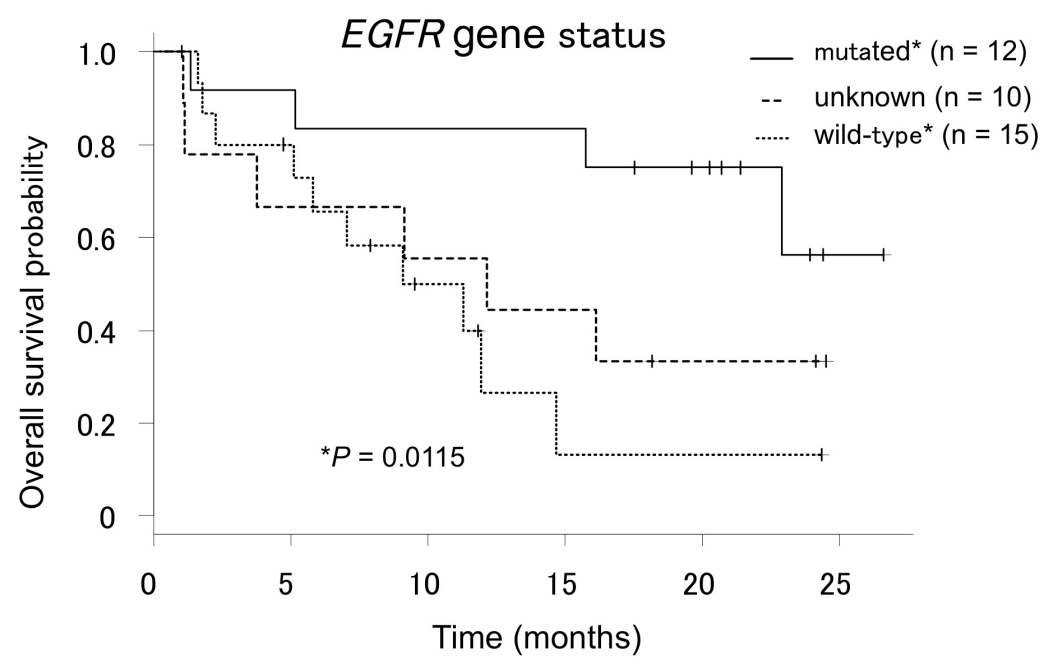

Figure 3. Kaplan-Meier survival plot according to EGFR gene mutation status (mutated, wild-type, unknown). The median OS in patients with EGFR mutations could not be determined, while that in patients with wild-type EGFR and unknown status were 9.2 months and 12.3 months, respectively. Statistically significant differences were observed between patients with and without mutations $(P=$ 0.0115, log-rank test). CI, confidence interval.

\section{Discussion}

For the entire cohort, we observed an ORR of 21.6\%, a DCR of 54.1\%, a median PFS time of 4.4 months, and a median OS time of 14.9 months. To date, some phase II and phase III trials of erlotinib have been reported. Of these, 2 Japanese prospective phase II studies had similar concepts to our study [14] [15]. Compared with these 2 trials, our results showed similar favorable responses. In these past 2 studies, responses to erlotinib were as follows: ORR, 28.3\% in both; DCR, 50.0\% and 47.8\%; median time to progression, 77 days and 75 days; and median OS, 14.7 months and 13.5 months, respectively. Patient characteristics were similar in these 2 studies, but patient characteristics in our study were different from these in some aspects. One of the major differences was the average age. On average, our patients were 9 years older, which likely explains the increased frequency of adverse events. Second, the proportion of patients with adenocarcinoma (70.3\%) in this study was much lower than that in the previous 2 studies (92\% and 87\%). These differences might explain the discrepancies in the responses observed. Because sensitive EGFR gene mutations are generally seen in patients with adenocarcinoma, and because this is the most important prognostic factor for treatment with EGFR-TKIs [19] [20], a high proportion of patients with adenocarcinoma in the previous studies may have resulted in the better outcome observed. Despite such disadvantages, our results were as promising as previous Japanese studies. Compared with a previous Western study, our results were much more encouraging. In the BR.21 trial [6], the ORR, PFS, and OS were 8.9\%, 2.2 months, and 6.7 months, respectively. These differences may depend on patient backgrounds; for examples, the percentages of Asian patients and adenocarcinoma cases in BR.21 were as low as $12.9 \%$ and $50.4 \%$, respectively.

In a stratified analysis, the survival of patients with EGFR mutations was similar but slightly superior to that of a previous Japanese trial [16]. Our patients showed a median PFS of 12.6 months, and the median OS was not yet reached. Meanwhile, Yamada et al. [16] reported a PFS of 9.3 months (OS, not yet determined). Surprisingly, our PFS (12.6 months) in this previously treated group was as long as those observed not only in 2 first-line Japanese gefitinib trials [9] [11] (10.8 months and 9.2 months, respectively), but also in first-line Chinese and European erlotinib trials (13.1 months in OPTIMAL [21], 9.4 months in EURTAC [22]). As suggested, EGFR mutations have been strongly correlated with positive responses not only to gefitinib but also to erlotinib [23]. Meanwhile, our patients with wild-type EGFR had a median PFS of 2.1 months and a median OS of 9.2 months, which were very close to those reported by previous Japanese trials [12] [13], with a PFS of 2.1 months in both studies and an OS of 9.2 months and 7.7 months. Although the TOPICAL trial demonstrated that first-line erlotinib treatment for patients in a poor health condition is controversial [24] and the recent TAILOR trial in Italy 
showed that second-line erlotinib treatment for patients with wild-type EGFR was not superior to standard chemotherapy [25]], our results indicate that erlotinib is beneficial for Japanese NSCLC patients even after failure of first-line therapy.

The toxicities commonly observed in this trial were mostly tolerable. In addition to diarrhea (24.3\%), skin disorders $(70.3 \%)$ and stomatitis (35.1\%) were the main forms of erlotinib toxicity, which were mostly manageable, as previously reported [6] [8]. With respect to skin disorders, our data also suggested that development of severe rash during erlotinib therapy could be associated with improved survival, as previously reported [26]. Furthermore, severe hematological toxicities were not observed, and therefore, many patients could continue therapy for long periods and maintain their activities of daily life. For instance, 1 patient received erlotinib for as long as 490 days.

Importantly, 3 patients (8.1\%) developed ILD, and unfortunately, 1 of these patients died. Two of these patients developed ILD within 3 weeks from the initiation of therapy. As previously reported [8], ILD is a relatively rare but potentially life-threatening complication, with an overall incidence of less than $1 \%$ in Caucasian patients and approximately 5\% in Japanese patients, and ILD occurred within a month in most cases. An ILD occurrence of $8.1 \%$ in this study is relatively high, compared to 2 other Japanese phase II trials [14] [15], with incidences of $6.5 \%$ and $4.3 \%$. This difference is probably due to the small sample size. Further studies may clarify the molecular mechanisms of the EGFR-TKI-induced ILD. Although the potential ILD risk in Japanese patients is not negligible, our results indicated that erlotinib has survival benefits as second- or third-line chemotherapy for EGFR non-selected NSCLC patients.

\section{Conclusion}

In summary, erlotinib was efficacious and well tolerated in Japanese patients with previously treated NSCLC. EGFR mutation status was the definitive predictive factor for erlotinib therapy. It is important to be especially aware of the risk of interstitial pneumonia for Japanese patients. Our results showed that erlotinib is a key drug for second- or third-line chemotherapy in patients with NSCLC.

\section{Acknowledgements}

We thank Drs. Takeshi Nakajima, Mayuka Isaka, Mami Inayama, Emiko Hosokawa, and Kazuki Anabuki for their participation in enrolling patients and providing information for the study.

\section{Financial Disclosure}

This work was supported in part by a Grant-in-Aid for Scientific Research of the Japanese Ministry of Education, Culture, Sports, Science, and Technology. The authors report no conflicts of interest to declare.

\section{References}

[1] Matsuda, T., Marugane, T., Kamo, K., Katanoda, K., Ajiki, W., Sobue, T. and Japan Cancer Surveilance Research Group (2012) Cancer Incidence and Incidence Rates in Japan in 2006: Based on Data from 15 Population-Based Cancer Registries in the Monitoring of Cancer Incidence in Japan (MCIJ) Project. Japanese Journal of Clinical Oncology, 42, 139-147. http://dx.doi.org/10.1093/jico/hyr184

[2] Siegel, R., Naishadham, D. and Jemal, A. (2013) Cancer Statistics, 2013. CA: A Cancer Journal for Clinitians, 63, 1130. http://dx.doi.org/10.3322/caac.21166

[3] Herbst, R.S., Heymach, J.V. and Lippman, S.M. (2008) Lung Cancer. New England Journal of Medicine, 359, 1367-1380. http://dx.doi.org/10.1056/NEJMra0802714

[4] Schiller, J.H., Harrington, D., Belani, C.P., Langer, C., Sandler, A., Krook, J., Zhu, J., Johnson, D.H. and Eastern Cooperative Oncology Group (2002) Comparison of Four Chemotherapy Regimens for Advanced Non-Small-Cell Lung Cancer. New England Journal of Medicine, 346, 92-98. http://dx.doi.org/10.1056/NEJMoa011954

[5] Ciardiello, F. and Tortora, G. (2008) EGFR Antagonists in Cancer Treatment. New England Journal of Medicine, 358, 1160-1174. http://dx.doi.org/10.1056/NEJMra0707704

[6] Shepherd, F.A., Rodrigues Pereira, J.R., Ciuleanu, T., Tan, E.H., Hirsh, V., Thongprasert, S., Campos, D., Maoleekoonpiroj, S., Smylie, M., Martins, R., Van Kooten, M., Dediu, M., Findlay, B., Tu, D., Johnston, D., Bezjak, A., Clark, G., Santabárbara, P., Seymour, L. and National Cancer Institute of Canada Clinical Trials Group (2005) Erlotinib in 
Previously Treated Non-Small-Cell Lung Cancer. New England Journal of Medicine, 353, 123-132. http://dx.doi.org/10.1056/NEJMoa050753

[7] Johnson, J.R., Cohen, M., Sridhara, R., Chen, Y.F., Williams, G.M., Duan, J., Gobburu, J., Booth, B., Benson, K., Leighton, J., Hsieh, L.S., Chidambaram, N., Zimmerman, P. and Pazdur, R. (2005) Approval Summary for Erlotinib for Treatment of Patients with Locally Advanced or Metastatic Non-Small Cell Lung Cancer after Failure of at Least One Prior Chemotherapy Regimen. Clinical Cancer Research, 11, 6414-6421. http://dx.doi.org/10.1158/1078-0432.CCR-05-0790

[8] Cataldo, V.D., Gibbons, D.L., Pérez-Soler, R. and Quintás-Cardama, A. (2011) Treatment of Non-Small-Cell Lung Cancer with Erlotinib or Gefitinib. New England Journal of Medicine, 364, 947-955. http://dx.doi.org/10.1056/NEJMct0807960

[9] Maemondo, M., Inoue, A., Kobayashi, K., Sugawara, S., Oizumi, S., Isobe, H., Gemma, A., Harada, M., Yoshizawa, H., Kinoshita, I., Fujita, Y., Okinaga, S., Hirano, H., Yoshimori, K., Harada, T., Ogura, T., Ando, M., Miyazawa, H., Tanaka, T., Saijo, Y., Hagiwara, K., Morita, S., Nukiwa, T. and North-East Japan Study Group (2010) Gefitinib or Chemotherapy for Non-Small-Cell Lung Cancer with Mutated EGFR. New England Journal of Medicine, 362, 2380-2388. http://dx.doi.org/10.1056/NEJMoa0909530

[10] Mok, T.S., Wu, Y.L., Thongprasert, S., Yang, C.H., Chu, D.T., Saijo, N., Sunpaweravong, P., Han, B., Margono, B., Ichinose, Y., Nishiwaki, Y., Ohe, Y., Yang, J.J., Chewaskulyong, B., Jiang, H., Duffield, E.L., Watkins, C.L., Armour, A.A. and Fukuoka, M. (2009) Gefitinib or Carboplatin-Paclitaxel in Pulmonary Adenocarcinoma. New England Journal of Medicine, 361, 947-957. http://dx.doi.org/10.1056/NEJMoa0810699

[11] Mitsudomi, T., Morita, S., Yatabe, Y., Negoro, S., Okamoto, I., Tsurutani, J., Seto, T., Satouchi, M., Tada, H., Hirashima, T., Asami, K., Katakami, N., Takada, M., Yoshioka, H., Shibata, K., Kudoh, S., Shimizu, E., Saito, H., Toyooka, S., Nakagawa, K., Fukuoka, M. and West Japan Oncology Group (2010) Gefitinib versus Cisplatin plus Docetaxel in Patients with Non-Small-Cell Lung Cancer Harbouring Mutations of the Epidermal Growth Factor Receptor (WJTOG3405): An Open Label, Randomized Phase 3 Trial. Lancet Oncology, 11, 121-128. http://dx.doi.org/10.1016/S1470-2045(09)70364-X

[12] Yoshioka, H., Hotta, K., Kiura, K., Takigawa, N., Hayashi, H., Harita, S., Kuyama, S., Segawa, Y., Kamei, H., Umemura, S., Bessho, A., Tabata, M., Tanimoto, M. and Okayama Lung Cancer Study Group (2010) A Phase II Trial of Erlotinib Monotherapy in Pretreated Patients with Advanced Non-Small Cell Lung Cancer Who Do Not Possess Active EGFR Mutations. Journal of Thoracic Oncology, 5, 99-104. http://dx.doi.org/10.1097/JTO.0b013e3181c20063

[13] Kobayashi, T., Koizumi, T., Agatsuma, T., Yasuo, M., Tsushima, K., Kubo, K., Eda, S., Kuraishi, H., Koyama, S., Hachiya, T. and Ohura, N. (2012) A Phase II Trial of Erlotinib in Patients with EGFR Wild-Type Advanced NonSmall-Cell Lung Cancer. Cancer Chemotherapy and Pharmacology, 69, 1241-1246. http://dx.doi.org/10.1007/s00280-012-1831-0

[14] Kubota, K., Nishiwaki, Y., Tamura, T., Nakagawa, K., Matsui, K., Watanabe, K., Hida, T., Kawahara, M., Katakami, N., Takeda, K., Yokoyama, A., Noda, K., Fukuoka, M. and Saijo, N. (2008) Efficacy and Safety of Erlotinib Monotherapy for Japanese Patients with Advanced Non-Small Cell Lung Cancer. A phase II Study. Journal of Thoracic Oncology, 3, 1439-1445. http://dx.doi.org/10.1097/JTO.0b013e31818d6702

[15] Takahashi, T., Yamamoto, N., Nukiwa, T., Mori, K., Tsuboi, M., Horai, T., Masuda, N., Eguchi, K., Mitsudomi, T., Yokota, S., Segawa, Y., Ichinose, Y., Fukuoka, M. and Saijo, N. (2010) Phase II Study of Erlotinib in Japanese Patients with Advanced Non-Small Cell Lung Cancer. Anticancer Research, 30, 557-563.

[16] Yamada, K., Takayama, K., Kawakami, S., Saruwatari, K., Morinaga, R., Harada, T., Aragane, N., Nagata, S., Kishimoto, J., Nakanishi, Y. and Ichinose, Y. (2013) Phase II Trial of Erlotinib for Japanese Patients with Previously Treated Non-Small-Cell Lung Cancer Harboring EGFR Mutations: Results of Lung Oncology Group in Kyusyu (LOGiK0803). Japanese Journal of Clinical Oncology, 43, 629-635. http://dx.doi.org/10.1093/jico/hyt056

[17] Yoshida, K., Yatabe, Y., Park, J.Y., Shimizu, J., Horio, Y., Matsuo, K., Kosaka, T., Mitsudomi, T. and Hida, T. (2007) Prospective Validation for Prediction of Gefitinib Sensitivity by Epidermal Growth Factor Receptor Gene Mutation in Patients with Non-Small Cell Lung Cancer. Journal of Thoracic Oncology, 2, 22-28. http://dx.doi.org/10.1097/01243894-200701000-00006

[18] Nagai, Y., Miyazawa, H., Huqun, Tanaka, T., Udagawa, K., Kato, M., Fukuyama, S., Yokote, A., Kobayashi, K., Kanazawa, M. and Hagiwara, K. (2005) Genetic Heterogeneity of the Epidermal Growth Factor Receptor in Non-Small Cell Lung Cancer Cell Lines Revealed by a Rapid and Sensitive Detection System, the Peptide Nucleic Acid-Locked Nucleic Acid PCR Clamp. Cancer Research, 65, 7276-7282. http://dx.doi.org/10.1158/0008-5472.CAN-05-0331

[19] Lynch, T.J., Bell, D.W., Sordella, R., Gurubhagavatula, S., Okimoto, R.A., Brannigan, B.W., Harris, P.L., Haserlat, S.M., Supko, J.G., Haluska, F.G., Louis, D.N., Christiani, D.C., Settleman, J. and Haber, D.A. (2004) Activating Mutations in the Epidermal Growth Factor Receptor Underlying Responsiveness of Non-Small-Cell Lung Cancer to Gefitinib. New England Journal of Medicine, 350, 2129-2139. http://dx.doi.org/10.1056/NEJMoa040938 
[20] Engleman, J.A. and Jänne, P.A. (2005) Factors Predicting Response to EGFR Tyrosine Kinase Inhibitors. Seminars in Respiratory and Critical Care Medicine, 26, 314-322. http://dx.doi.org/10.1055/s-2005-871990

[21] Zhou, C., Wu, Y.L., Chen, G., Feng, J., Liu, X.Q., Wang, C., Zhang, S., Wang, J., Zhou, S., Ren, S., Lu, S., Zhang, L., Hu, C., Hu, C., Luo, Y., Chen, L., Ye, M., Huang, J., Zhi, X., Zhang, Y., Xiu, Q., Ma, J., Zhang, L. and You, C. (2011) Erlotinib versus Chemotherapy as First-Line Treatment for Patients with Advanced EGFR Mutation-Positive NonSmall-Cell Lung Cancer (OPTIMAL, CTONG-0802): A Multicenter, Open-Label, Randomized, Phase 3 Study. Lancet Oncology, 12, 735-742. http://dx.doi.org/10.1016/S1470-2045(11)70184-X

[22] Rosell, R., Carcereny, E., Gervais, R., Vergnenegre, A., Massuti, B., Felip, E., Palmero, R., Garcia-Gomez, R., Pallares, C., Sanchez, J.M., Porta, R., Cobo, M., Garrido, P., Longo, F., Moran, T., Insa, A., De Marinis, F., Corre, R., Bover, I., Illiano, A., Dansin, E., De Castro, J., Milella, M., Reguart, N., Altavilla, G., Jimenez, U., Provencio, M., Moreno, M.A., Terrasa, J., Muñoz-Langa, J., Valdivia, J., Isla, D., Domine, M., Molinier, O., Mazieres, J., Baize, N., Garcia-Campelo, R., Robinet, G., Rodriguez-Abreu, D., Lopez-Vivanco, G., Gebbia, V., Ferrera-Delgado, L., Bombaron, P., Bernabe, R., Bearz, A., Artal, A., Cortesi, E., Rolfo, C., Sanchez-Ronco, M., Drozdowskyj, A., Queralt, C., De Aguirre, I., Ramirez, J.L., Sanchez, J.J., Molina, M.A., Taron, M., Paz-Ares, L. and Spanish Lung Cancer Group in Collaboration with Groupe Français de Pneumo-Cancérologie and Associazione Italian Oncologia Toracica (2012) Erlotinib versus Standard Chemotherapy as First-Line Treatment for European Patients with Advanced EGFR Mutation-Positive NonSmall-Cell Lung Cancer (EURTAC): A Multicenter, Open-Label, Randomized Phase 3 Trial. Lancet Oncology, 13, 239-246. http://dx.doi.org/10.1016/S1470-2045(11)70393-X

[23] Smith, J. (2005) Erlotinib: Small-Molecule Targeted Therapy in the Treatment of Non-Small-Cell Lung Cancer. Clinical Therapeutics, 27, 1513-1534. http://dx.doi.org/10.1016/j.clinthera.2005.10.014

[24] Lee, S.M., Khan, I., Upadhyay, S., Lewanski, C., Falk, S., Skailes, G., Marshall, E., Woll, P.J., Hatton, M., Lal, R., Jones, R., Toy, E., Chao, D., Middleton, G., Bulley, S., Ngai, Y., Rudd, R., Hackshaw, A. and Boshoff, C. (2012) First-Line Erlotinib in Patients with Advanced Non-Small-Cell Lung Cancer Unsuitable for Chemotherapy (TOPICAL): A Double-Blind, Placebo-Controlled, Phase 3 Trial. Lancet Oncology, 13, 1161-1170. http://dx.doi.org/10.1016/S1470-2045(12)70412-6

[25] Garassino, M.C., Martelli, O., Broggini, M., Farina, G., Veronese, S., Rulli, E., Bianchi, F., Bettini, A., Longo, F., Moscetti, L., Tomirotti, M., Marabese, M., Ganzinelli, M., Lauricella, C., Labianca, R., Floriani, I., Giaccone, G., Torri, V., Scanni, A., Marsoni, S. and TAILOR Trialists (2013) Erlotinib versus Docetaxel as Second-Line Treatment of Patients with Advanced Non-Small-Cell Lung Cancer and Wild-Type EGFR Tumors (TAILOR): A Randomized Control Trial. Lancet Oncology, 14, 981-988. http://dx.doi.org/10.1016/S1470-2045(13)70310-3

[26] Pérez-Soler, R., Chachoua, A., Hammond, L.A., Rowinsky, E.K., Huberman, M., Karp, D., Rigas, J., Clark, G.M., Santabárbara, P. and Bonomi, P. (2004) Determinants of Tumor Response and Survival with Erlotinib in Patients with Non-Small-Cell Lung Cancer. Journal of Clinical Oncology, 22, 3238-3247. http://dx.doi.org/10.1200/JCO.2004.11.057 